\title{
Article
}

\section{Fire resistance of additively manufactured water filled polymer part}

Brooks, Hadley Laurence, Wright, Chris, Harris, Stephen Anthony and Fsadni, Andrew

Available at http://clok.uclan.ac.uk/25318/

Brooks, Hadley Laurence ORCID: 0000-0001-9289-5291, Wright, Chris, Harris, Stephen Anthony and Fsadni, Andrew ORCID: 0000-0003-3047-2714 (2018) Fire resistance of additively manufactured water filled polymer part. Additive Manufacturing, 22 . pp. 138-145. ISSN 2214-7810

It is advisable to refer to the publisher's version if you intend to cite from the work. http://dx.doi.org/10.1016/j.addma.2018.04.015

For more information about UCLan's research in this area go to http://www.uclan.ac.uk/researchgroups/ and search for <name of research Group>.

For information about Research generally at UCLan please go to http://www.uclan.ac.uk/research/

All outputs in CLoK are protected by Intellectual Property Rights law, including Copyright law. Copyright, IPR and Moral Rights for the works on this site are retained by the individual authors and/or other copyright owners. Terms and conditions for use of this material are defined in the policies page.

\section{CLoK}

Central Lancashire online Knowledge www.clok.uclan.ac.uk

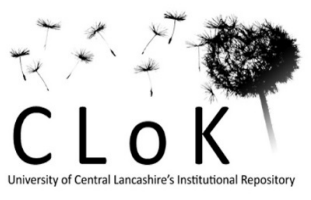


Fire resistance of additively manufactured water filled polymer parts.

H. Brooks, C. Wright, S. Harris, A. Fsadni

Abstract:

This paper introduces the concept of additively manufactured (AM) water filled parts (WFPs). By combining the energy absorbing properties of water with polymers it is possible to significantly improve time to ignition of AM parts with open internal structures. Theory relating the flame temperature to the maximum wall temperature of WFPs is developed. A range of water-polymer configurations are presented as a basis for WFP designs. Three separate thermal experiments were conducted to test different aspects of the WFPs. The time to ignition for cone calorimetry samples was extended $794 \%$ over plain photopolymers. Case studies were used to demonstrate the effectiveness of WFPs with complex shapes. The results of thermo-fluid finite element simulations showed good agreement with experimental observations and provide a useful tool for the evaluation and optimisation of WFP designs. The fire resistance of thin walled structures were found to be significantly improved by adding water. The water filling strategy was found to be more effective than adding intumescent coatings. Finally further work and recommendations are discussed.

Keywords: Additive manufacturing; fire resistance; water; polymer; heat transfer.

Highlights:

- A novel concept of water filled parts (WFPs) is introduced.

- The WFPs show excellent fire resistance.

- Thermo-fluid FEA modelling was shown to be useful in predicting WFP performance.

\section{Introduction}

\subsection{Background}

An important consideration for the use of additive manufactured (AM) polymers in high fire risk areas, is the polymers flammability and heat strength [1]. Of the 345 polymers listed on Senvol's additive manufacturing database only eight are currently rated V-0 according to the UL 94 standard [2]. The $\mathrm{V}-\mathrm{O}$ rated polymers are either high performance plastics (PEEK, PEAK, PEI or PPSF) or contain chemical flame retardants. Processing polymers with high thermal performance such as PEEK is more expensive than polymers like PA12, due to higher material costs, higher processing temperatures and low powder recyclability [3-6]. Polymers in general also suffer from fairly low heat deflection temperatures ranging from $38-263^{\circ} \mathrm{C}$ at $0.45 \mathrm{MPa}$, a property not improved by adding flame retardants [2]. At $300-400^{\circ} \mathrm{C}$ most polymers begin to decompose releasing flammable volatiles which add further fuel to flames [7-11]. There is extensive research aimed at improving the flame retarding properties of polymers. This is done in three main ways: (i) developing inherently flame retardant polymers, (ii) chemically modifying polymers and (iii) adding flame retardant particles to polymers [12]. Polymers with flame retardants often require high particle loadings which can negatively affect the mechanical properties $[13,14]$, reduce recyclability and introduce harmful chemicals, such as halogens, into the environment [15-17]. Polymers used in AM have additional 
constraints when considering adding flame retardants, as processing often requires a very narrow range of stock material properties, such as powder flowability, particle size distribution, heat absorption, polymer viscosity and the stability of colloids or suspensions in photopolymer resins [18, 19].

Another strategy to improve the fire resistance of polymers is to add a thermal barrier coating. A number of different coatings have been developed to insulate load-bearing substrates from fire using mineral refractories or intumescent materials [20]. They all function by forming a low density, air or gas-containing structure which achieves its thermal resistance by immobilising the gas within it. The thermal conductivity of such structures is generally of the order of $0.01-0.05 \mathrm{~W} / \mathrm{mK}$, regardless of the type of material [1]. While thermal barrier coatings are proven to be effective they are often not viable in many applications due to their added weight, low durability, appearance and solubility in water [21, 22].

This paper presents a simple, effective and environmentally benign method for improving the fire resistance of AM parts, without the use of specially formulated polymers or coatings, simply by filling them with water. These components will be referred to as water filled parts (WFPs). The concept is based on the well-known class room physics demonstration where a paper bag is filled with water and placed over a flame. The paper does not burn, not because it is wet, but because the water absorbs the heat keeping the paper below its ignition temperature.

\subsection{Water filled parts (WFPs)}

The concept of improving fire resistance by filling structures with water is not new and has been applied to large steel structures [23,24]. Adding water to fire resistant fabric laminates has also been investigated via the addition of hydrogel layers [25]. This is believed to be the first study of its kind with a focus on the flame resistance of small complex polymer parts.

Polymers with low thermal conductivity and specific heat result in materials with surfaces that can rapidly increase in temperature when subjected to a heat source, such as a flame. Table 1 provides thermal conductivity and specific heat capacity data for some common materials. Note that water has a very high gravimetric and volumetric specific heat capacity. Water also has the benefit of being a fluid at room temperature, capable of high convective heat transfer and has a large latent heat of vaporisation. All of these properties make water an excellent choice to combine with polymers to improve the fire resistance of the printed parts.

Table 1. Thermal conductivities and specific heats of common materials.

\begin{tabular}{|l|c|c|c|}
\hline \multirow{2}{*}{ Material } & Thermal conductivity & \multicolumn{2}{c|}{ Specific heat capacity } \\
\cline { 3 - 4 } & at $25^{\circ} \mathrm{C}(\mathrm{W} / \mathrm{m} \mathrm{K})$ & $(\mathrm{J} / \mathrm{kg} \mathrm{K})$ & $\left(\mathrm{J} / \mathrm{m}^{3} \mathrm{~K}\right)$ \\
\hline PA 6 & 0.25 & 1600 & 1824 \\
\hline PLA & 0.13 & 1800 & 2340 \\
\hline Air & 0.024 & 1005 & 1231 \\
\hline Wood (oak) & 0.17 & 2000 & 1833 \\
\hline Steel & 43 & 490 & 3822 \\
\hline Aluminium & 205 & 870 & 2484 \\
\hline Water & 0.58 & 4182 & 4190 \\
\hline Concrete & 1.7 & 880 & 2122 \\
\hline
\end{tabular}

Understandably, water cannot be mixed into the polymer before printing so space must be made inside the part for the water at the design stage. Most polymer AM technologies are capable 
of producing hollow parts with open internal structures that provide space for the water. For powder bed fusion, vat polymerisation and material extrusion methods these porous structures can then be filled with water in a post-build process and subsequently sealed (Figure 1a). It may also be necessary to make the polymer part watertight before adding the water by coating with a sealant $[26,27]$. Material jetting technologies can be used to print the polymer and water simultaneously [28], avoiding the need for a two part process and allowing isolated and functionally graded internal volumes of water (Figure 1b). For thick parts where weight reduction is a concern a double shell structure can be used, as shown in Figure 1c. If the surface of the part is likely to be damaged then multiple shells may be added for redundancy. It is also possible to combine different strategies to find the right combination of strength, durability and weight.

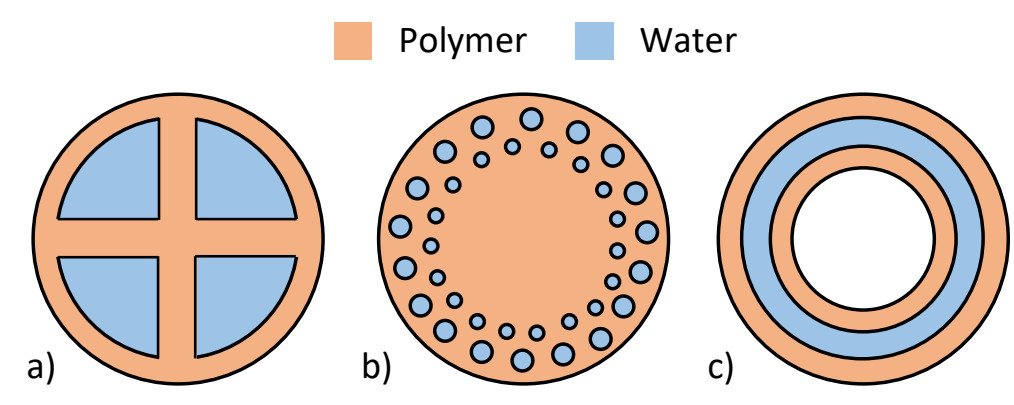

Figure 1. Cross sections of three water/polymer configurations: a) A hollow or open lattice structure filled with water, b) Functionally graded water volumes, c) double shell structure with water trapped between the inner and outer polymer shells.

Another important design consideration is the build-up of pressure within WFPs as the water is heated. Many polymers will soften sufficiently at $100^{\circ} \mathrm{C}$ such that a thin wall (less than $1 \mathrm{~mm}$ thick) will leak at relatively low pressures. For thick walled parts with softening temperatures over $100^{\circ} \mathrm{C}$ it may be necessary to include pressure relief points designed to preferentially vent when internal pressures start to rise above unsafe levels.

\subsection{Heat transfer theory}

Instantaneous heat transfer across a polymer wall, involves both convection and conduction as described by Equation 1. As heat transfers through the wall the water will increase in temperature until it reaches $100^{\circ} \mathrm{C}$.

$$
\dot{Q}=\frac{A}{\left[\frac{1}{h_{h}}+\frac{t_{p}}{k}+\frac{1}{h_{c}}\right]}\left(T_{h}-T_{c}\right)
$$

$A=$ the wall surface area, $h_{h}=$ the effective convective heat transfer coefficient on the hot side, $t_{p}=$ the wall thickness, $k=$ the polymer conductivity, $h_{c}=$ the convective heat transfer coefficient on the cold side, $T_{h}=$ Temperature of the hot side, $T_{c}=$ Temperature of the cold side.

The convective heat transfer coefficient on the water side is highly temperature dependant and varies between surfaces with different material combinations, surface roughness and local geometries. To simplify this problem the water can be assumed to be $100^{\circ} \mathrm{C}$ until the water has completely converted to steam. The high temperature of the water is compensated for by the 
extremely high convective heat transfer rates present during boiling. If this assumption is made the problem becomes static and the heat transfer and wall temperatures do not change with time.

The temperature of the wall surfaces is related to the temperature difference between the flame, water, and the heat flow described by Equation 2.

$$
T_{h}-T_{c}=\left(T_{h}-T_{h w}\right)+\left(T_{h w}-T_{c w}\right)+\left(T_{c w}-T_{c}\right)=\frac{\dot{Q}}{A}\left[\frac{1}{h_{c}}+\frac{t_{p}}{k}+\frac{1}{h_{h}}\right]
$$

where $T_{h w}=$ the hot side wall temperature, $T_{c w}=$ the cold side wall temperature.

Of critical importance is the maximum temperature of the polymer wall, $T_{h w}$. This can be calculated via Equation 3.

$$
T_{h w}=T_{c w}-\left(T_{c w}-T_{h}\right) /\left(\frac{h_{c}}{h_{h}}+\frac{t_{p} h_{c}}{k}+1\right)
$$

Assuming values for the heat transfer coefficients, polymer conductivity, flame temperature and water temperature, it is possible to investigate the effect of wall thickness and water temperature on the temperature profile across the polymer wall.

Table 2. Values used in Equations 1 - 3 to generate Figures 2 and 3.

\begin{tabular}{|c|c|c|}
\hline Parameter & Value & Units \\
\hline$t_{p}$ & $0.5 \times 10^{-3}$ to $2 \times 10^{-3}$ & $\mathrm{~m}$ \\
\hline$k$ & 0.2 & $\mathrm{~W} / \mathrm{mK}$ \\
\hline$h_{h}$ & 54.3 & $\mathrm{~W} / \mathrm{m}^{2} \mathrm{~K}$ \\
\hline$h_{c}$ & $=20\left(T_{c}\right)+500$ & $\mathrm{~W} / \mathrm{m}^{2} \mathrm{~K}$ \\
\hline$T_{c}$ & 273 to 373 & $\mathrm{~K}$ \\
\hline$T_{h}$ & 2026 & $\mathrm{~K}$ \\
\hline$A$ & 1 & $\mathrm{~m}^{2}$ \\
\hline
\end{tabular}

The values for $h_{h}$ and $T_{h}$ were adopted from the work of Wang et al. [29, 30] to represent the effective heat transfer coefficient and temperature of a flame consistent with UL 94 standards. The value for $k$ was chosen as a mid-range value for polymers. A linear relationship for $h_{c}$ was assumed, based on commonly quoted values for the convective heat transfer of water at 20 and $100^{\circ} \mathrm{C}$. Figure 2 shows the temperature profile across polymer walls of varying thicknesses for a water temperature of $100^{\circ} \mathrm{C}$. While the inside wall is maintained near $100^{\circ} \mathrm{C}$ for all thicknesses the outside wall temperature is almost linearly related to the wall thickness. For the $0.5 \mathrm{~mm}$ and $2.0 \mathrm{~mm}$ walls the maximum temperature is calculated to be $325^{\circ} \mathrm{C}$ and $697^{\circ} \mathrm{C}$ respectively. 


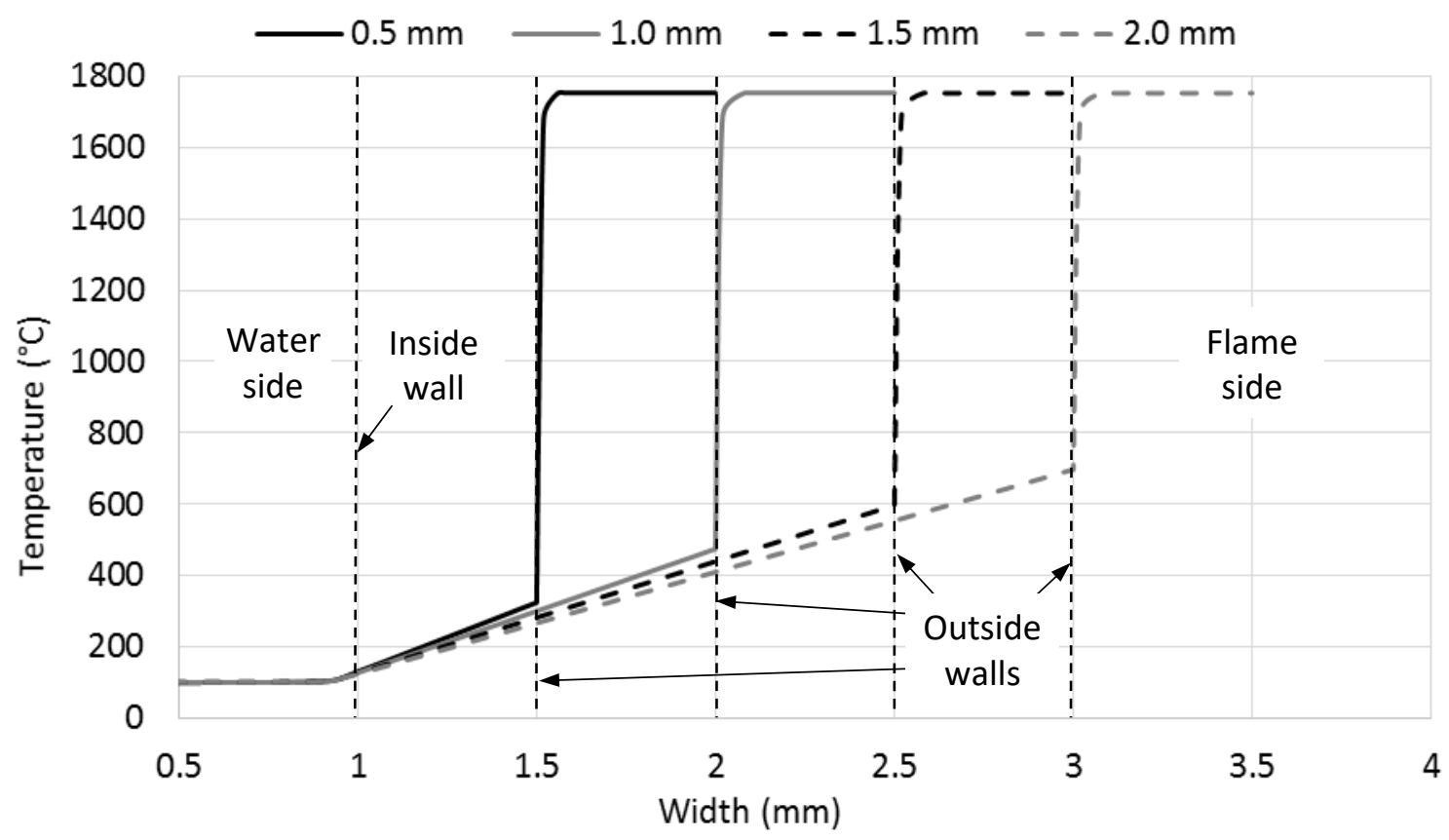

Figure 2. Temperature profiles across different polymer wall thicknesses for water at $100^{\circ} \mathrm{C}$.

Using the same equations it is possible to determine the effect of water temperature on the maximum wall temperature. The temperature profiles for $0.5 \mathrm{~mm}$ thick walls are shown in Figure 3 , revealing that the water temperature has little influence on the maximum polymer temperature. Surprisingly when the water is at $0^{\circ} \mathrm{C}$ the flame-side of the wall is slightly hotter than when the water is $100^{\circ} \mathrm{C}$. This is due to the fact the convective heat transfer of naturally convecting cold water is much lower than that of nucleate boiling water [31, 32].

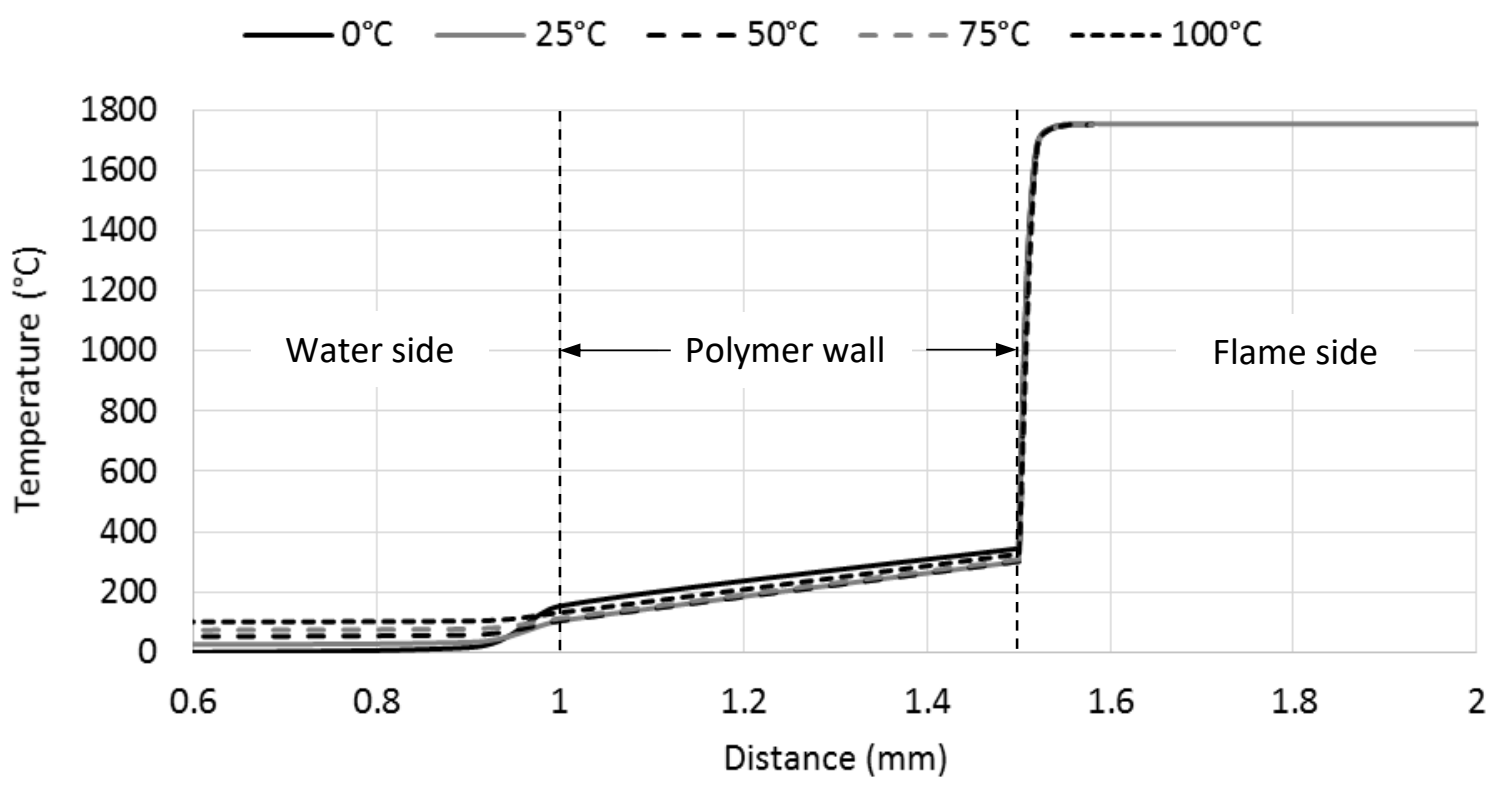

Figure 3. Temperature profiles for a $0.5 \mathrm{~mm}$ thick polymer wall with different water temperatures on the cold side. 
The equations also show the heat flow across the wall is inversely related to the wall thickness. This means that while thin walls lead to lower maximum wall temperatures the water will boil faster. The theory presented here provided initial estimates for the effective wall thicknesses used in the following studies.

\section{Experimental Method}

Three primary experiments were conducted to test different aspects of the WFPs. Cone calorimetry was used to assess how the WFPs coped with a radiant heat source from above and to determine how the heat release rate and smoke production rate are effected. The final two experiments were case studies: Case study 1 was aimed at investigating how the water affects a cantilevers ability to hold a load whilst being in contact with a flame. Case study 2 investigated if a relatively thin walled part with local features of high polymer to water ratio, can also be improved using this concept.

All samples were printed using a Formlabs Form1+ SLA printer and clear methacrylic photoactive resin (GPCLO2) with $0.1 \mathrm{~mm}$ layer heights. The as-printed samples were left on a window sill for a day to post cure. As this curing method is known to be inferior to UV curing the properties are likely to be closer to the green part properties shown in Table 3.

Table 3. Material properties for Formlabs clear resin (GPCL02) [33].

\begin{tabular}{|l|c|c|l|}
\hline \multicolumn{1}{|c|}{ Property } & Green & Post cured & Method \\
\hline Tensile strength at yield & $29.8 \mathrm{Mpa}$ & $61.5 \mathrm{MPa}$ & ASTM D 638-10 \\
\hline Young's modulus & $1.3 \mathrm{GPa}$ & $2.7 \mathrm{GPa}$ & ASTM D 638-10 \\
\hline Heat deflection temp. at 0.455 MPa & $325 \mathrm{~K}$ & $351 \mathrm{~K}$ & ASTM D 648-07 \\
\hline $5 \%$ weight loss temperature & $520 \mathrm{~K}$ & $547 \mathrm{~K}$ & ASTM E 1131 \\
\hline
\end{tabular}

Specific sample geometries are given in the following sections. The clear material allowed the initiation of boiling to be visually observed. For improved readability the results and discussion of each test will immediately follow the relevant methods section.

\subsection{Cone Calorimetry test}

\subsubsection{Method}

The cone calorimetry test was carried out in accordance with BS ISO 5660-1:2015 with an irradiance set at $35 \mathrm{~kW} / \mathrm{m}^{2}\left(702^{\circ} \mathrm{C}\right) 50 \mathrm{~mm}$ below the cone heater in order to measure the heat release rate, time to ignition and smoke production of the WFPs. The standard sample geometry was modified to allow a hollow internal cavity. $1 \mathrm{~mm}$ diameter support columns were added to improve the compressive strength of the samples during handling (Figure 4). Whilst samples in this test would normally be solid the WFPs are considered as metamaterials or polymer/water composites. Four holes were left in the shell to allow uncured resin to escape and were later sealed with hot melt adhesive. The tests were carried out in duplicate with two as-printed samples and two water filled samples. 


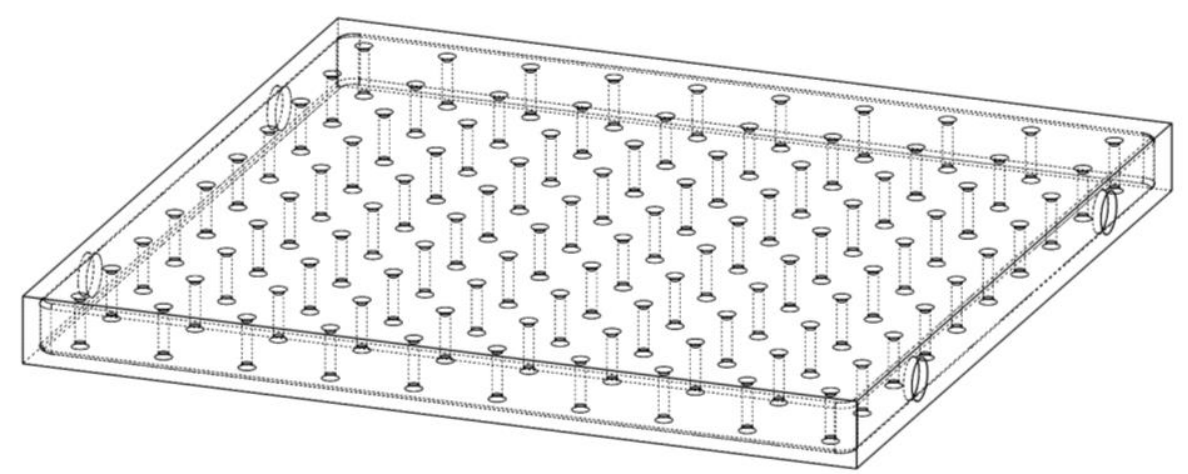

Figure 4. Cone calorimeter test samples, $100 \times 100 \times 8 \mathrm{~mm}$ with $1 \mathrm{~mm}$ thick shell and $1 \mathrm{~mm}$ diameter support columns spaced at $5 \mathrm{~mm}$ intervals.

\subsubsection{Results and discussion}

The average results of the cone calorimetry tests are summarised in Table 4. The time to sustained ignition for the water filled sample was 8 times longer than the unfilled sample. This test confirms that the cooling effect of the water is effective even when the heat is radiated from above and there is less benefit from convective heat transfer within the water volume.

Table 4. Average cone calorimetry results for samples with and without water.

\begin{tabular}{|l|c|c|}
\hline & Without water & With water \\
\hline Time to sustained ignition $(\mathrm{s})$ & 32 & 283 \\
\hline Peak rate of heat release $\left(\mathrm{kW} / \mathrm{m}^{2}\right)$ & 483 & 452 \\
\hline Post ignition smoke production $\left(\mathrm{m}^{2} / \mathrm{m}^{2}\right)$ & 442 & 269 \\
\hline
\end{tabular}

Once the majority of the water evaporated the water filled samples proceeded to burn with a similar intensity to the unfilled samples as shown by the heat release curves in Figure 5.

Without water —With water

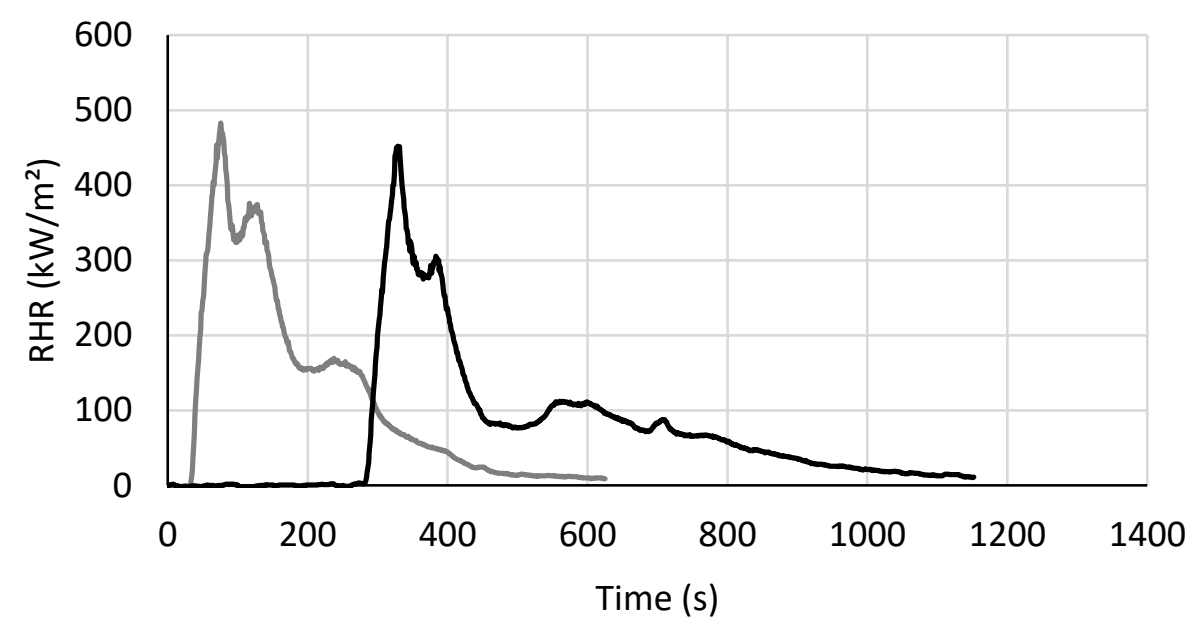

Figure 5. Rate of heat release for samples with and without water.

The maximum smoke production rate for the water filled sample was significantly lower than the unfilled sample and delayed by approximately 250 seconds (Figure 6 ). The total post 
ignition smoke production for the unfilled sample was measured to be $65 \%$ greater than the water filled sample.

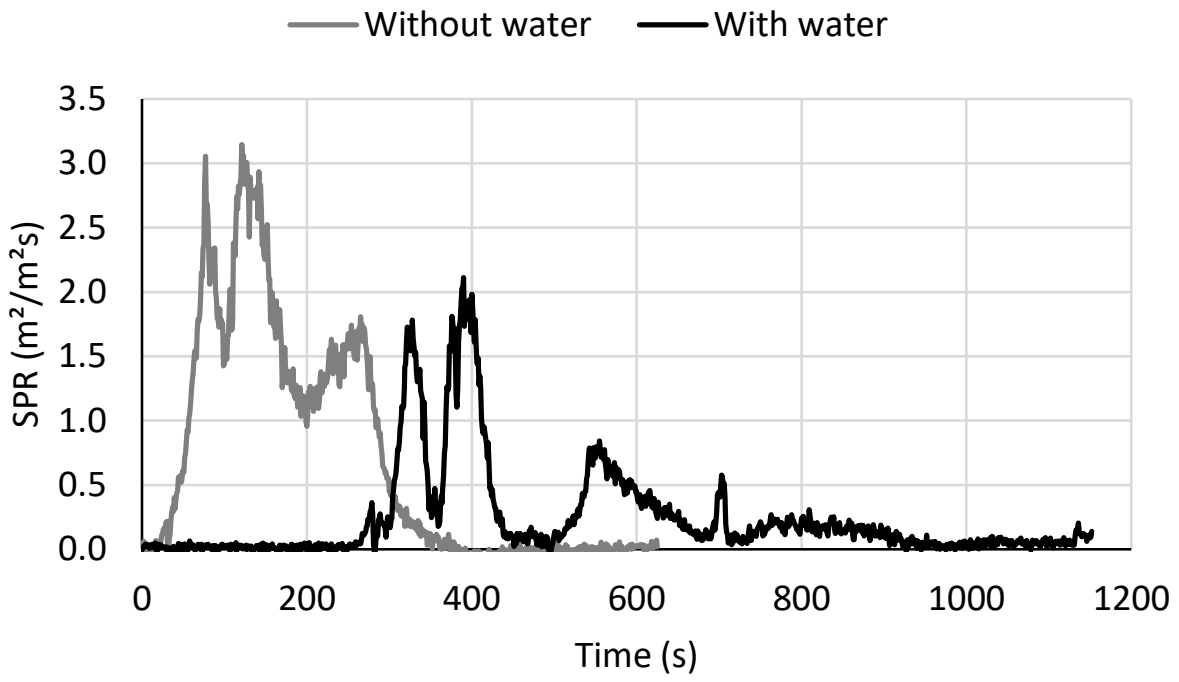

Figure 6. Smoke production rate versus time for samples with and without water.

Smoke production is analysed by measuring how the smoke attenuates a laser beam in the exhaust duct. The attenuation is related to volume flow, resulting in a measure of smoke density. It is unclear at this stage why the smoke production for the water filled sample was diminished. It is possible that, water vapour condensed in the exhaust duct, captured particles that would otherwise have attenuated the laser beam.

\subsection{Case study 1 - Load bearing cantilever}

Case study 1 was designed to test how WFPs will perform when subjected to both thermal and mechanical loads.

\subsubsection{Method}

Five cantilever designs were trialled. In all cases only the internal volume of the cantilevers was allowed to be altered. This was to reflect real world constraints that may reduce design freedoms. Figure 7 shows the overall shape of the cantilevers along with the five unique internal structures. The designs were chosen to cover the range from fully solid cross sections to completely hollow, with a range of intermediate structures in between. 


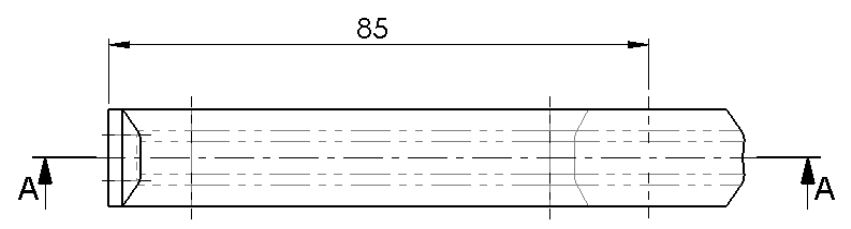

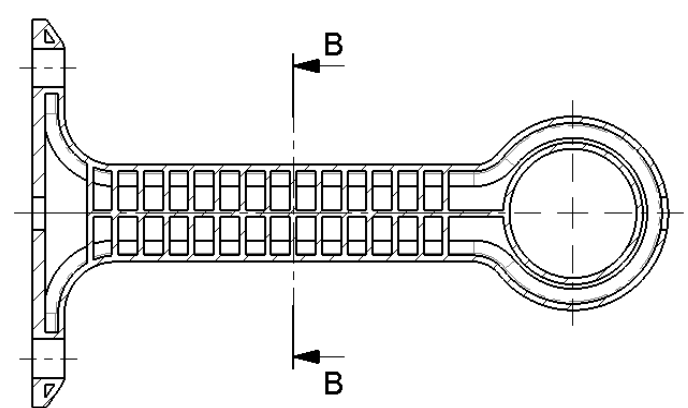

Section A

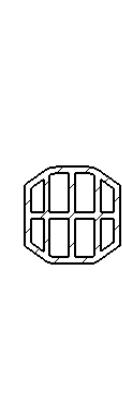

Section B
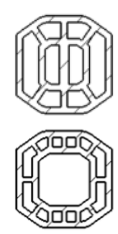

$\longrightarrow$

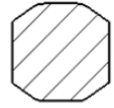

Other crosssections

Figure 7. Design of the cantilever specimen for the heat deflection case study. The basic structure of the lattice design $(\mathrm{L})$ is shown on the left. On the right are cross sections of the four other designs from top to bottom: Large shell (LS), Small shell (SS), Hollow (H) and Solid (S).

The two shell designs (LS and SS) each contained two discrete internal volumes so that it was possible to fill only the outer volume with water. The average weights of each of the designs (with and without water) is shown in Table 5 below. Approximately 1 gram of glue was used to seal each sample. The WFPs are slightly lighter than the solid samples.

Table 5. Weights of the cantilever samples with and without water.

\begin{tabular}{|l|c|c|c|}
\hline & As printed $(\mathrm{g})$ & Water filled $(\mathrm{g})$ & Water mass $(\mathrm{g})$ \\
\hline Solid (S) & 26 & NA & 0 \\
\hline Hollow (H) & 10.3 & 23.7 & 12.4 \\
\hline Lattice (L) & 11.1 & 24.2 & 12.1 \\
\hline Large shell (LS) & 14.1 & 22.3 & 7.2 \\
\hline Small shell (SS) & 14.3 & 20.3 & 5.0 \\
\hline
\end{tabular}

The first set of samples were loaded until failure at room temperature using calibrated weights to assess the relative strengths of the designs. These samples were not water filled. All tests were carried out in duplicate and the results averaged. To test the heat strength of the five designs a $50 \mathrm{~W}$ flame was applied to the straight section of the samples whilst supporting a $70 \mathrm{~g}$ load. For samples $\mathrm{H}$ and $\mathrm{S}$, the vertical deflection was recorded over time (Figure 8). Additionally an $\mathrm{H}$ sample was given an intumescent coating (consisting of sodium silicate and milled carbon fibre in a volumetric ratio of 10:1) to see how thermal barrier strategies compare with the WFPs. The milled carbon fibre was found to improve the durability of the coating and ease application. 


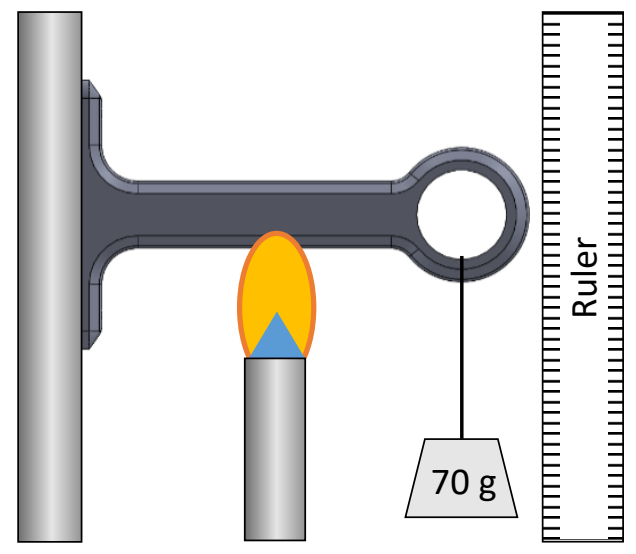

Figure 8. Experimental setup for the heat deflection case study.

\subsubsection{Results and discussion}

The results of the mechanical load tests showed the solid sample was approximately seven times stronger than WFP designs (Figure 9a). This is to be expected as the necessary thin walls of the WFPs significantly reduce the second moment of area of the samples. Internal support structures proved to have little influence on the ultimate strength of the WFPs compared to the completely hollow sample. The flame tests showed the water filled samples had significantly increased time to sustained ignition compared to the unfilled samples (Figure 9b). The water filled $\mathrm{H}$ and $\mathrm{L}$ designs failed due to softening of the polymer before they had a chance to ignite. The $\mathrm{S}$, LS and SS designs all eventually caught fire before failing. Whilst the solid sample caught fire relatively early it took 228 seconds to fracture. It was interesting to note that the cantilever samples were much more fire resistant than the equivalent ( $1 \mathrm{~mm}$ thick walled) UL 94 samples. This was clearly due to the absence of sharp corners and edges in the cantilever design.

- Maximum load at room temperature

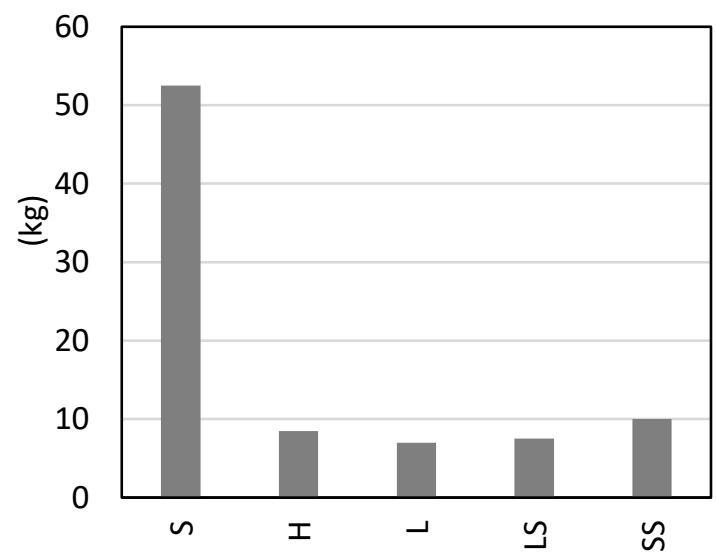

Without water

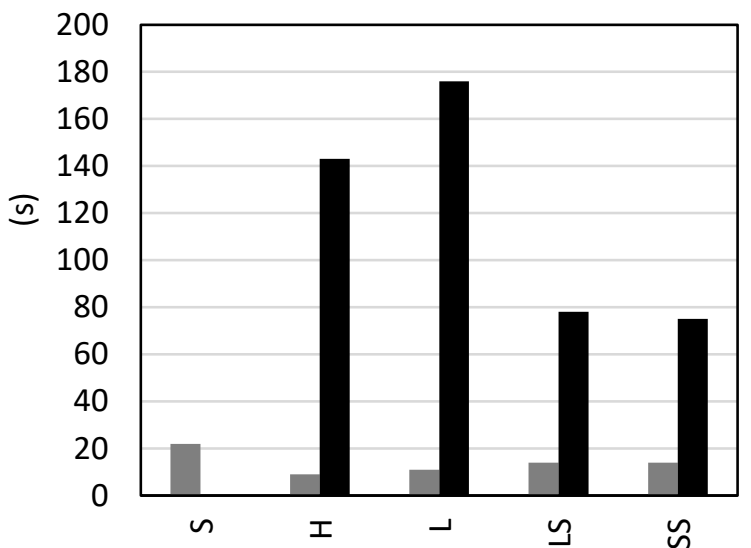

Figure 9. a) Average load at failure for cantilever designs at room temperature. b) Average time to sustained ignition for samples with and without water. Note: The water filled $\mathrm{H}$ and $\mathrm{L}$ designs failed before sustained ignition.

A key result of the flame tests is that if the flame had been removed after 60 seconds all of the WFPs would have survived. Additionally, if the flame was removed after 120 seconds the $\mathrm{H}$ and $\mathrm{L}$ water filled samples would have survived. Figure 10 shows the deflection of selected samples during 
the flame tests. The dry hollow sample ignited and failed very quickly. The intumescent coating was found to delay failure of a dry hollow sample only slightly. The solid sample ignited early but was sufficiently strong to outlast the hollow sample with the intumescent coating. The two water filled samples took the longest to ignite and to fail. Clearly the water filled and coated sample was able to withstand the direct application of the flame the longest.

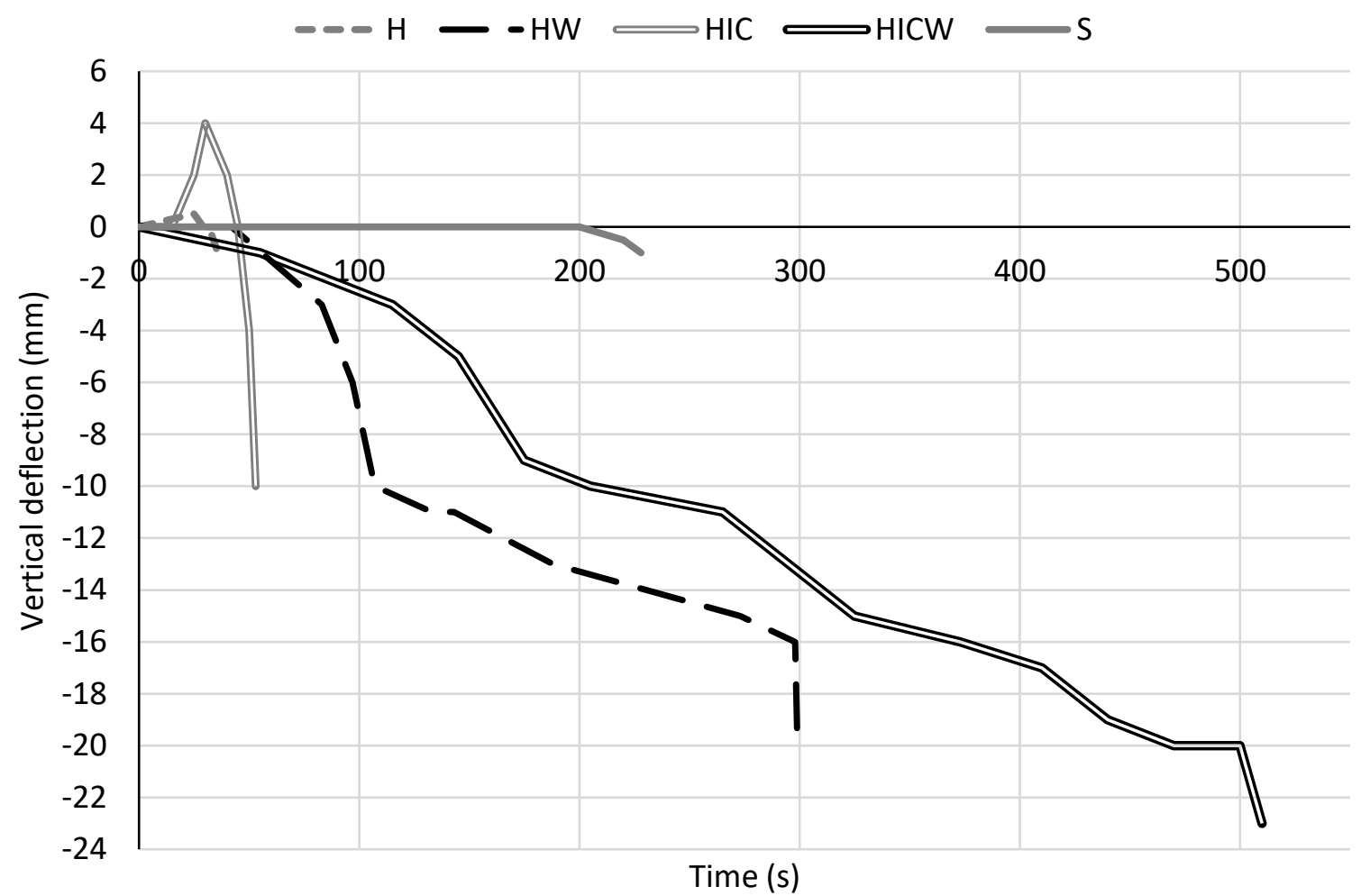

Figure 4. Vertical deflection of weighted cantilever samples with an applied flame. $\mathrm{H}$ (hollow), HW (hollow with water), HIC (hollow with intumescent coating), HIC (hollow with water and intumescent coating) and $\mathrm{S}$ (solid). Deflection measurements are within $\pm 1 \mathrm{~mm}$.

\subsubsection{Thermal modelling}

In order to understand the deflection characteristics of the hollow samples, finite element analysis (FEA) was used to simulate thermal conduction through the polymer walls and the subsequent internal convective fluid flow. Due to the lack of specific material property data for the cured resin, generic (mid-ranged) material property data for poly (metha methylacrylate) (PMMA) was used. Specifically $0.2 \mathrm{~W} / \mathrm{mK}, 1.18 \mathrm{~g} / \mathrm{cm}^{3}$ and $1466 \mathrm{~J} / \mathrm{kgK}$ for the thermal conductivity, density and specific heat capacity respectively. The material properties for air and water were taken without modification from the material library. The outer walls were assumed to be adiabatic whilst the heat from the flame was modelled by applying a heat transfer coefficient of $54.3 \mathrm{~W} / \mathrm{mK}$ and a flame temperature of $2026 \mathrm{~K}$ to the bottom $10 \mathrm{~mm}$ of the sample, based on the findings of Wang et al. [29, 30]. The outer walls were assumed to be adiabatic whilst the heat from the flame was modelled by applying a $54.3 \mathrm{~W} / \mathrm{mK}$ heat transfer coefficient and a flame temperature of $2026 \mathrm{~K}$ across a $20 \mathrm{~mm}$ wide section on the bottom surfaces. The $20 \mathrm{~mm}$ width is an estimate of the flame spread arrived at from experimental observation. The side walls directly above the flame were also given a $54.3 \mathrm{~W} / \mathrm{mK}$ heat transfer coefficient with half the flame temperature (1013 K). The aim of the simulation was to model the warming phase and not boiling or combustion, hence the simulation of the water filled sample was stopped once the average water temperature reached $373.15 \mathrm{~K}$. The hollow (dry) 
simulation was stopped after 15 seconds. The time steps were set to 1 second for the water filled simulations and 0.5 seconds for the air filled simulation as further reductions in time step did not significantly change the results in either case. Automatic refinement of the mesh for solid cells and for narrow channels was enabled.

Table 6 presents a series of cut plots showing the temperature along the central plane of the cantilever at various times. The colour scheme was chosen to best display the progression of critical polymer temperatures throughout the part over time. The heat deflection temperature (ASTM D 648-07) at $0.455 \mathrm{MPa}$ for the resin used in the experiments is $325 \mathrm{~K}$ for green parts and $351 \mathrm{~K}$ for parts post-cured with UV light [33]. The $70 \mathrm{~g}$ weight used in the experiment produces a maximum stress in the cantilever of $0.45 \mathrm{MPa}$ (determined by static FEA at room temperature) which means the heat deflection temperature provided is comparable. The SLA parts used in the experiments were cured in sunlight as opposed to UV light and so are likely to be closer to the green material properties presented in Table 3.

Table 6. Cut plots showing the distribution of temperature from 325K (blue) to $520 \mathrm{~K}$ (red). Gray areas are under $325 \mathrm{~K}$ and purple areas are over $520 \mathrm{~K}$.

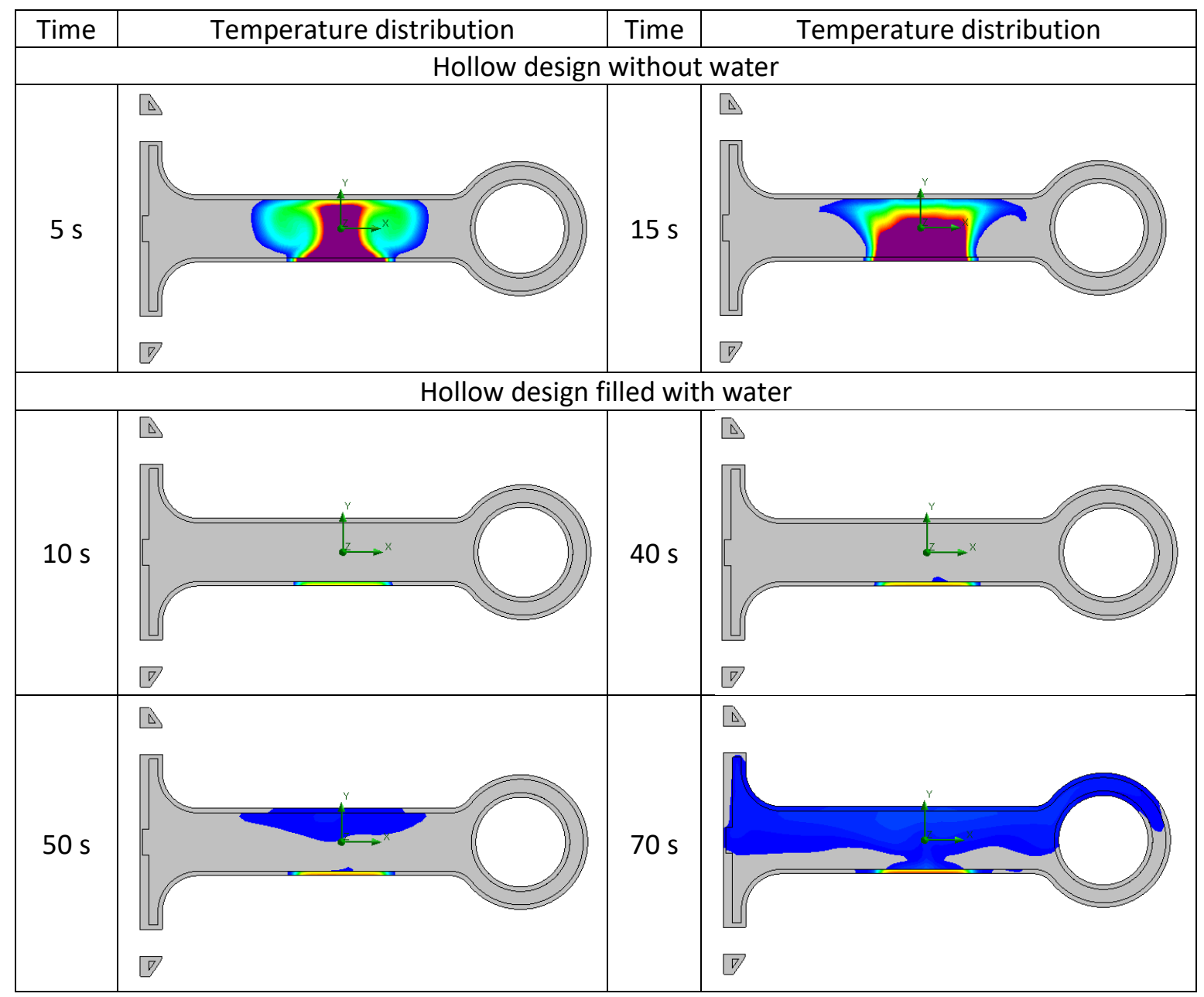




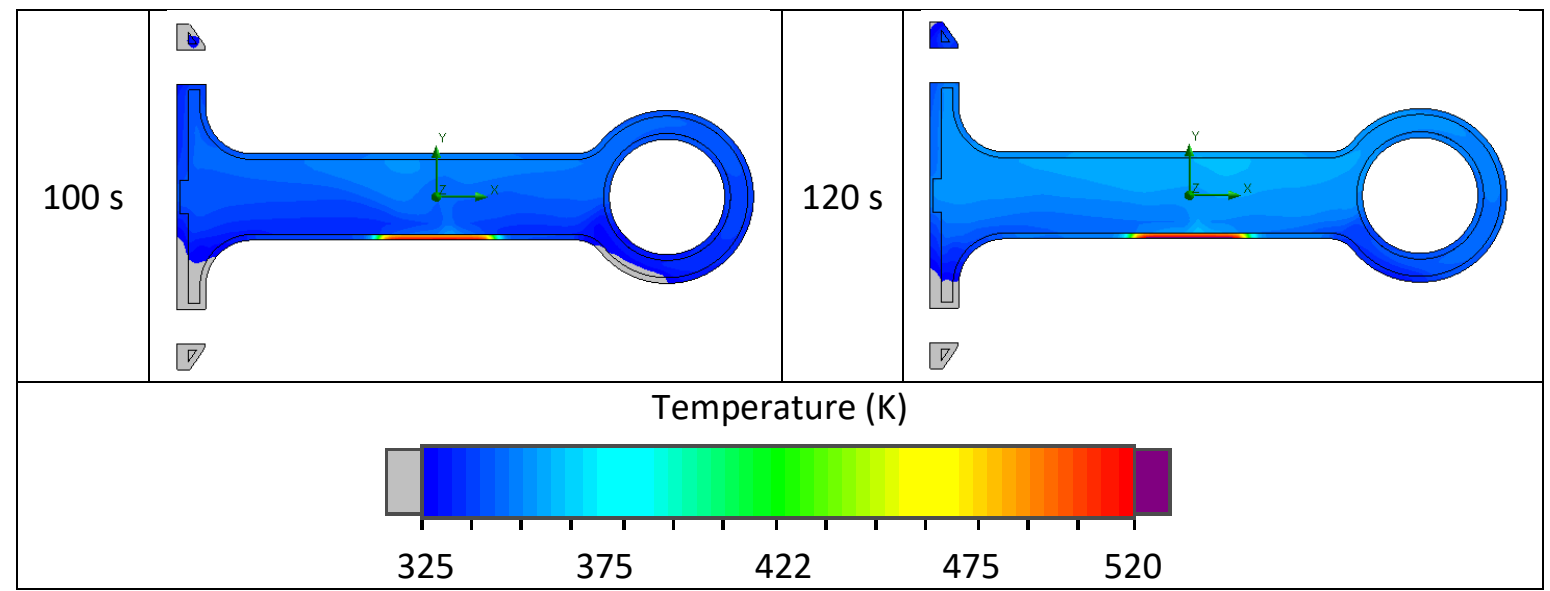

The simulations provide a very useful indicator of how the parts heat up over time. For the unfilled simulation it is clear that after 15 seconds a significant volume of polymer at the flame location is above the $5 \%$ weight loss temperature of $520 \mathrm{~K}$. This relates well with the known ignition time of 9-18 seconds. For the water filled sample the proportion of material above the heat deflection temperature of $325 \mathrm{~K}$ increases dramatically between 50 and 100 seconds. This correlates well with the rapid increase in deflection seen in the experimental test.

The results demonstrate that thermo-fluid simulations are an effective tool for understanding the ignitability and warming characteristics of WFPs. Coupling the thermo-fluid simulation results with a mechanical analysis could allow the prediction of deformation and stress overtime.

\subsection{Case study 2 - Thin walled object}

For WFPs to be widely applicable it is important to know whether it is possible to improve the fire resistance of thin parts. There are many situations where the thickness of the parts may be limited, reducing the total volume available for water and greatly reducing local water:polymer ratios.

\subsubsection{Methodology}

A $40 \mathrm{~mm}$ computer fan housing was redesigned as shown in Figure 11.
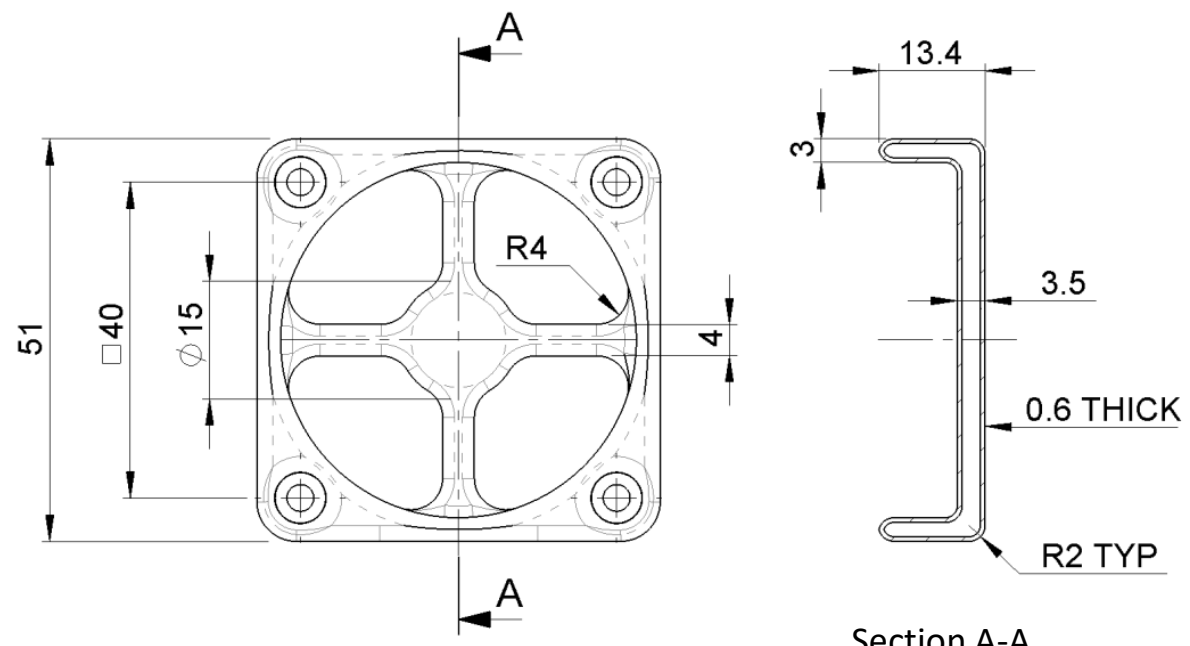

Section A-A

Figure 5. Design of the shelled $40 \mathrm{~mm}$ computer fan housing for case study 2. 
The functional dimensions of the housing were unchanged while the wall thickness was increased from $1.5 \mathrm{~mm}$ to $3.5 \mathrm{~mm}$ and shelled with $0.6 \mathrm{~mm}$ walls. Four samples were printed, one was left as printed, one was filled with water, one was coated with an intumescent coating and one was filled with water and coated.

The fans were tested in the vertical orientation with a $50 \mathrm{~W}$ flame centred $10 \mathrm{~mm}$ below the part. The time to boil and time to ignition was recorded for the water filled sample.

\subsubsection{Results and discussion}

Both of the water filled samples had significantly longer times to sustained ignition than the unfilled samples. Unsurprisingly the water filled and coated sample survived direct contact with the flame the longest. A summary of the results are shown in Table 7.

Table 7. Results of computer fan housing case study.

\begin{tabular}{|l|c|c|c|c|}
\hline water & $\begin{array}{c}\text { Housing without } \\
\text { wathout water } \\
\text { withousing }\end{array}$ & $\begin{array}{c}\text { Water filled } \\
\text { housing }\end{array}$ & $\begin{array}{c}\text { Water filled and } \\
\text { coated housing }\end{array}$ \\
\hline $\begin{array}{l}\text { Photos taken } 11 \\
\text { seconds from the } \\
\text { first application of } \\
\text { the flame. }\end{array}$ \\
$\begin{array}{l}\text { Come } \\
\text { Time for boiling to } \\
\text { start (s) }\end{array}$
\end{tabular}

For the water filled sample $28 \%$ of the time to ignition was spent heating the water to boiling point. The rest of the time was spent evaporating the water before ignition could take place. This case study demonstrates that even very thin sections may significantly benefit from internal water cooling providing the fluid is free to move within the part. An additional finding is that the part should be designed with the preferential leak point located near the top of the part so that the water cannot escape due to gravity until it is converted to steam.

\section{Conclusions}

This paper introduced the concept of water filled parts (WFPs). By combining the energy absorbing properties of water with polymer parts it is possible to significantly improve the time to ignition. The technique may also be applied to rotation moulded parts and other manufacturing methods that allow the production of hollow shells. Additive manufacturing is particularly appropriate as it allows open internal lattices to be printed which can significantly increase the part 
strength. In practice it was found that polymer walls approximately $1 \mathrm{~mm}$ thick provided a good compromise between strength and fire resistance as long as sharp corners were avoided.

The time to ignition for cone calorimetry samples (where the radiant heat source comes from above) was significantly extended. Measurements showed smoke production was reduced by half, although this result needs further verification. Case studies were used to demonstrate the effectiveness of WFPs with complex shapes. The fire resistance of thin walled structures was also found to be significantly improved, as long as the small water cavity near the flame was connected to water elsewhere in the part. The cantilever case study showed that the WFPs are significantly weaker than solid parts due to the bending stresses being highest in the thin outer walls. This will limit the usefulness of WFPs in many applications. A factor that goes someway to mitigate this problem is that many functional AM parts are already deliberately printed with sparse internal structures to increase build speed and reduce materials cost. The results of thermo-fluid finite element simulations showed good agreement with experimental observations and provide a useful tool for the evaluation and optimisation of WFPs. WFPs were compared with samples with intumescent coatings and the results indicate that WFPs delay the time to ignition more effectively than intumescent coatings.

For brevity the authors have only presented the results based on photo-polymerised resin parts however similar results for the cone calorimetry tests were seen with extruded PLA and laser sintered PA6 WFPs. It is likely that other high performance polymers such as PEEK or PPSF would also benefit from integrated internal water volumes. Whilst the fire resistance of WFPs has been validated there are still questions surrounding part durability, polymer degradation, biological contamination, cost and the best method for sealing the parts. Durability could be improved by maximising wall thickness and the internal lattice structures. Material jetting could provide a higher resolution water distribution allowing functionally graded water volumes within parts. Additional redundancy could be possible by implementing multiple discrete cavities in an onion layer structure. Biological inhibitors will be needed to prevent the growth of bacteria, viruses, protozoans and mould. Adding graphite powder, nanoparticles or other flame resistant thermally conductive materials to the water may improve performance by increasing heat transfer and providing additional fire resistance once the water has evaporated. Polymers which degrade in the presence of water should be modified or avoided where long life is required. Hydrogels may be a suitable replacement for water, reducing the chance of premature leakage.

\section{Acknowledgments}

The authors of the current investigation would like to thank the University of Central Lancashire UK, for facilitating the completion of this study as well as the various authors who have been contacted during the course of this study.

\section{References}

1. Christke, S., et al., Multi-layer polymer metal laminates for the fire protection of lightweight structures. Materials \& Design, 2016. 97: p. 349-356.

2. Senvol, Senvol Database. 2016: http://senvol.com/database/.

3. Berretta, S., K.E. Evans, and O. Ghita, Processability of PEEK, a new polymer for High Temperature Laser Sintering (HT-LS). European Polymer Journal, 2015. 68: p. 243-266. 
4. Rahman, K.M., T. Letcher, and R. Reese. Mechanical Properties of Additively Manufactured PEEK Components Using Fused Filament Fabrication. in ASME 2015 International Mechanical Engineering Congress and Exposition. 2015. American Society of Mechanical Engineers.

5. Rechtenwald, T., et al., Comparison between laser sintering of PEEK and PA using design of experiment methods. 2005.

6. Schmidt, M., D. Pohle, and T. Rechtenwald, Selective Laser Sintering of PEEK. CIRP Annals Manufacturing Technology, 2007. 56(1): p. 205-208.

7. Beyler, C.L. and M.M. Hirschler, Thermal decomposition of polymers. SFPE handbook of fire protection engineering, 2002. 2: p. 110-131.

8. Levchik, S.V., Introduction to flame retardancy and polymer flammability. Flame retardant polymer nanocomposites, 2007: p. 1-29.

9. Lu, S.X., P. Cebe, and M. Capel, Thermal stability and thermal expansion studies of PEEK and related polyimides. Polymer, 1996. 37(14): p. 2999-3009.

10. Ohkita, T. and S.-H. Lee, Thermal degradation and biodegradability of poly (lactic acid)/corn starch biocomposites. Journal of Applied Polymer Science, 2006. 100(4): p. 3009-3017.

11. Pearce, E., Flame-retardant polymeric materials. 2012: Springer Science \& Business Media.

12. Laoutid, F., et al., New prospects in flame retardant polymer materials: From fundamentals to nanocomposites. Materials Science and Engineering: R: Reports, 2009. 63(3): p. 100-125.

13. Camino, G., et al., Effect of hydroxides and hydroxycarbonate structure on fire retardant effectiveness and mechanical properties in ethylene-vinyl acetate copolymer. Polymer Degradation and Stability, 2001. 74(3): p. 457-464.

14. Owen, S.R. and J.F. Harper, Mechanical, microscopical and fire retardant studies of $A B S$ polymers. Polymer Degradation and Stability, 1999. 64(3): p. 449-455.

15. Bourbigot, S. and S. Duquesne, Fire retardant polymers: recent developments and opportunities. Journal of Materials Chemistry, 2007. 17(22): p. 2283-2300.

16. de Wit, C.A., An overview of brominated flame retardants in the environment. Chemosphere, 2002. 46(5): p. 583-624.

17. Wang, R. and Z. Xu, Recycling of non-metallic fractions from waste electrical and electronic equipment (WEEE): A review. Waste Management, 2014. 34(8): p. 1455-1469.

18. Guo, N. and M.C. Leu, Additive manufacturing: technology, applications and research needs. Frontiers of Mechanical Engineering, 2013. 8(3): p. 215-243.

19. Gibson, I., D. Rosen, and B. Stucker, Additive Manufactruing Technologies. 2010: Springer US.

20. Wang, X., et al., Flame retardancy and thermal properties of novel UV-curing epoxy acrylate coatings modified by phosphorus-containing hyperbranched macromonomer. Journal of Polymer Research, 2013. 20(7): p. 1-11.

21. Wang, Z., E. Han, and W. Ke, Influence of expandable graphite on fire resistance and water resistance of flame-retardant coatings. Corrosion Science, 2007. 49(5): p. 2237-2253.

22. Sakumoto, Y., et al., Durability Evaluation of Intumescent Coating for Steel Frames. Journal of Materials in Civil Engineering, 2001. 13(4): p. 274-281.

23. Seigel, L., Water-Filled Tubular Steel Columns-Fire Protection without Coating. Civil Engineering, 1967. 37(9): p. 65-\&.

24. Seigel, L.G., Designing for fire safety with exposed structural steel. Fire Technology, 1970. 6(4): p. 269-278.

25. Illeperuma, W.R.K., et al., Fire-Resistant Hydrogel-Fabric Laminates: A Simple Concept That May Save Lives. ACS Applied Materials and Interfaces, 2016. 8(3): p. 2071-2077.

26. Zhu, J., et al., Water-based coatings for 3D printed parts. Journal of Coatings Technology and Research, 2015. 12(5): p. 889-897.

27. Mireles, J., et al. Analysis of sealing methods for FDM-fabricated parts. in Proceeding from Solid Free-form Fabrication Symposium. 2011. 
28. MacCurdy, R., et al., Printable Hydraulics: A Method for Fabricating Robots by 3D Co-Printing Solids and Liquids. arXiv preprint arXiv:1512.03744, 2015.

29. Wang, Y., et al., Analysis and Modeling of Ignitability of Polymers in the UL-94 Vertical Burning Test Condition. Journal of Fire Sciences, 2009. 27(6): p. 561-581.

30. Wang, Y., et al., Development of the unsteady upward fire model to simulate polymer burning under UL94 vertical test conditions. Fire Safety Journal, 2012. 54: p. 1-13.

31. Zhao, Y., T. Tsuruta, and C. Ji, Experimental study of nucleate boiling heat transfer enhancement in a confined space. Experimental Thermal and Fluid Science, 2003. 28(1): p. 916.

32. Rops, C.M., et al., Enhanced heat transfer in confined pool boiling. International Journal of Heat and Fluid Flow, 2009. 30(4): p. 751-760.

33. Inc, F., Clear: Photopolymer Resin for Form 1+. 2014: www.formlabs.com. 